\title{
Laser Soldering and Laser Droplet Joining for Mechanical and Electrical Contacting of LTCC/PZT Laminates
}

\author{
Florian Albert", Carolin Pfeiffer ${ }^{*}$, Michael Schmidt ${ }^{* * * *}$, Manfred Geiger $^{*}$, Markus Flössel ${ }^{* * *}$ and Alexander Michaelis ${ }^{* * *}$ \\ ${ }^{*}$ Bayerisches Laserzentrum GmbH, Konrad-Zuse-Straße 2-6, D-91052 Erlangen, Germany \\ E-mail: f.albert@blz.org \\ *** Friedrich-Alexander-Universität Erlangen-Nürnberg, Chair of Photonic Technologies, \\ Paul-Gordan-Straße 3, D-91052 Erlangen, Germany \\ E-mail: michael.schmidt@lpt.uni-erlangen.de \\ *** Technische Universität Dresden, Institute of Material Science, Chair of Inorganic Non-Metallic \\ Materials, Winterbergstraße 28, D-01062 Dresden, Germany \\ E-mail: markus.floessel@ikts.fraunhofer.de
}

\begin{abstract}
Present research in the field of active noise reduction for automotive components deals with piezoelectric laminates embedded into parts like aluminium gear boxes, car bodies or clutch housings fabricated by die casting or forced-locked insertion. Under closed loop operation, these parts are able to modify the oscillation behaviour and noise of the whole construction. Precondition for such solutions are specially designed laminates which guarantee power transmission into the parts as well as reproducible electrical and mechanical connections between the laminates and the electrical contacts. PZT actuators which are embedded in Low Temperature Cofired Ceramic (LTCC) laminates are promising for this application. This paper discusses current results of laser soldering and laser droplet joining on LTCC/PZT samples with screen printed silver pads. Laser soldered contacts allow the application of the laminates in automotive parts subjected to low thermal loads. The experimental setup for the realisation of laser solder joints on the laminates is described and the results of micrograph analysis and shear force measurements are discussed. For high temperature stable connections laser droplet joining with brazing material is used. The thermal energy of the applied molten droplets needs to be adjusted in order to prevent the laminates and their pads from being damaged. The process technology and results for the creation of crack-free connections are described.
\end{abstract}

DOI:10.2961/jlmn.2011.01.0016

Keywords: LTCC/PZT Laminates, Laser Soldering, Laser Droplet Joining

\section{Introduction}

LTCC/PZT laminates - embedded e.g. into automotive parts - may control the dynamic properties of thin-walled structures providing both sensing and actuating functions as well as significantly reducing the noise emission. Different concepts are being pursued like embedding piezoceramic fibres into sheet metals or LTCC/PZT laminates into die casting parts, see figure 1 [1-4].

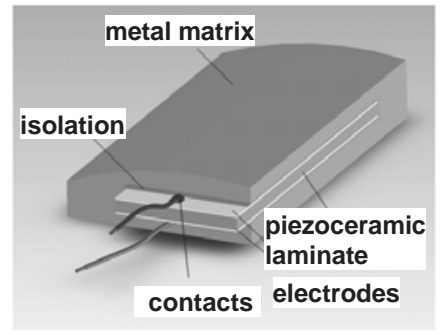

Fig. 1 Piezoceramic LTCC/PZT laminate embedded into a die casting part

The connections between the piezoelectric laminates and the electric circuits are normally achieved by means of clamping or conventional soldering with a soldering iron. Disadvantages are the low process rate (relevant especially for large-volume production) as well as quality problems due to the non-contactless joining method.

Laser micro welding and soldering are robust, fast and non-contact joining techniques that are well established in the high power electronics manufacturing sector. These as well as laser droplet joining could be used to connect LTCC/PZT components to power circuitry. The main challenge is to realise crack-free, reliable, mechanical and (especially for further processing via metal die casting) also temperature stable joints.

\section{Material and Experimental Set-up}

\subsection{LTCC/PZT Laminates}

The following examinations were carried out on screen printed and sintered silver pads. They were applied on Low Temperature Cofired Ceramic (LTCC) Heralock ${ }^{\circledR}$ HL2000 green tape [5] supplied by Heraeus. This green tape is also used as substrate material for LTCC/PZT Sensor-ActuatorModules as described in [6].

Before screen-printing, the LTCC was laminated. Therefore the green tapes were preconditioned in a convection oven with $\mathrm{T}=80^{\circ} \mathrm{C}$ and $\mathrm{t}=10$ minutes. Subsequently, two LTCC green tapes were laminated in an isostatic lamination system (PTC IL 4008) with a pressure of 
$\mathrm{p}=172$ bar at $\mathrm{T}=75^{\circ} \mathrm{C}$ for $\mathrm{t}=10$ minutes to get a tape with a thickness of about $t_{L}=260 \mu \mathrm{m}$. After laminating, solderable silver pads were applied. For this, a special complementary silver based paste TC0306 supplied by Heraeus was used. The pad thickness was controlled by repeat printing with an EKRA M2-K screen printer. The LTCC green tape and screen printed paste were cofired in a box furnace with a special firing profile and a maximum temperature of $\mathrm{T}=865^{\circ} \mathrm{C}$. After sintering, the LTCC has a thickness of $t_{L}=220 \mu \mathrm{m}$ and the thicknesses of the silver pads are $t_{P}=20 \mu \mathrm{m}$ and $t_{P}=34 \mu \mathrm{m}$, respectively.

For the laser soldering tests, the silver pads were arranged to fit a SO8 chip layout, as shown in figure 2.
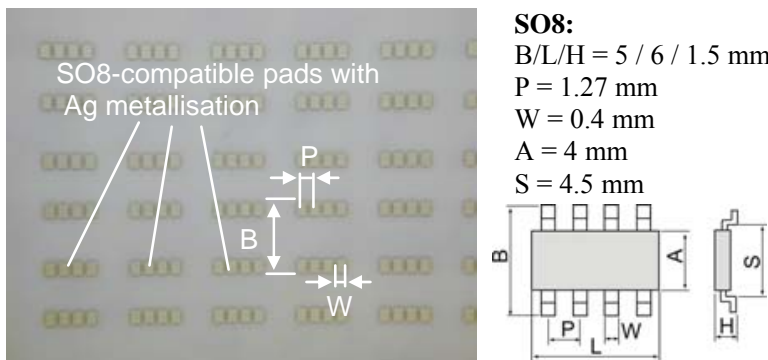

Fig. 2 LTCC Heralock ${ }^{\circledR}$ HL2000 with screen printed silver solder pads for SO8 (left); SO8 electronic element (right)

For the laser droplet joining experiments, 28 round silver pads were printed on one sample, as shown in figure 3.

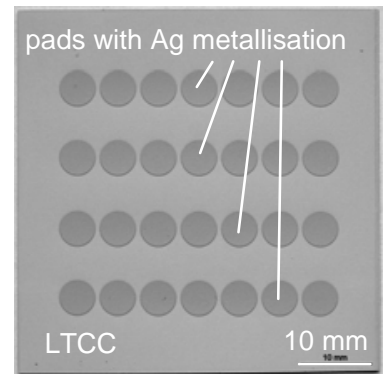

Fig. 3 LTCC Heralock ${ }^{\circledR}$ HL2000 green tape with 28 screen printed silver pads

\subsection{Laser Soldering}

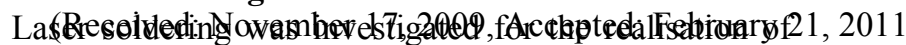

contacts for parts operating under low thermal load. In these experiments, copper wires with a diameter of $\mathrm{d}_{\mathrm{W}}=200 \mu \mathrm{m}$ as well as electronic components with a SO8 chip design were applied on the LTCC/PZT laminates. A diode laser with a wavelength of $\lambda=940 \mathrm{~nm}$ and a maximum power of $\mathrm{P}=50 \mathrm{~W}$ was used as beam source. The focused spot size of this setup was $1000 \mu \mathrm{m} \times 700 \mu \mathrm{m}$. The laser energy was applied under a closed-loop laser power control. The temperature at the solder joints was measured during the soldering process by the use of a pyrometer with an operating wavelength of $\lambda=2.4 \mu \mathrm{m}$. The maximum temperature at all investigations was $30{ }^{\circ} \mathrm{C}$ to $50{ }^{\circ} \mathrm{C}$ above the melting point of the solder.

A solder paste of $\mathrm{Sn} 96.5 \mathrm{Ag} 3 \mathrm{Cu} 0.5$ was used with a resin-based flux supplied by GLT and conforming to the ROL0 standard. The melting temperature of this solder paste is $\mathrm{T}_{\text {melt }}=219^{\circ} \mathrm{C}$. In figure 4 the experimental setup is shown.

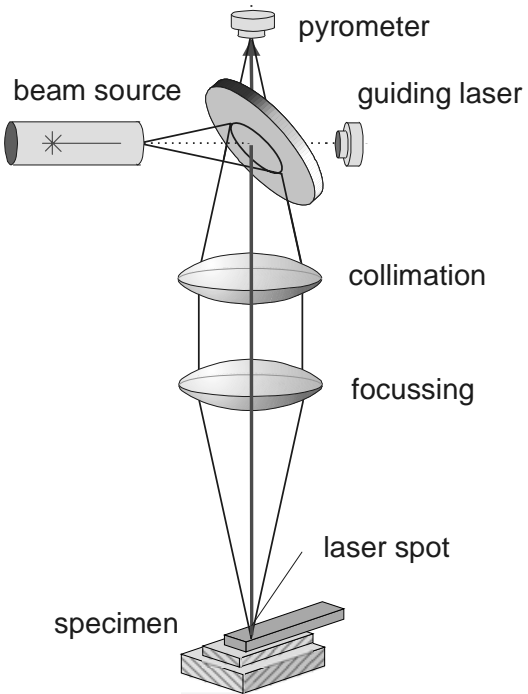

Fig. 4 Schematic of the experimental setup for laser soldering

\subsection{Laser Droplet Joining}

Laser droplet joining (LDJ) is a process involving either brazing or welding, which allows the creation of more temperature-resistant joints. Such contacts are necessary for parts operating under a high thermal load or components which, after joining, are processed via die casting. In that case, they undergo a high temperature treatment which might remelt the solder joints.

In laser droplet joining, the melting point of the chosen additional material determines the joining process (i.e. whether welding or brazing). In these investigations, a double-beam setup using one pulsed Nd:YAG-laser with a wavelength of $\lambda=1064 \mathrm{~nm}$, two optical fibres $\left(\mathrm{d}_{\text {Fibre }}=400 \mu \mathrm{m} ; \quad \mathrm{NA}=0.12\right) \quad$ and process heads $\left(\mathrm{f}_{\text {Foc. }}=100 \mathrm{~mm} ; \mathrm{d}_{\text {Spot }}=280 \mu \mathrm{m}\right)$, a wire feeding system with positioning nozzle and a shielding gas supply was used. The wire (B-Cu75AgP-645; $d=1 \mathrm{~mm} ; \mathrm{T}_{\text {melt }}=645^{\circ} \mathrm{C}$ ) was fed vertically into the focus of the two laser beams in order to allow a brazing process, see figure 5 .

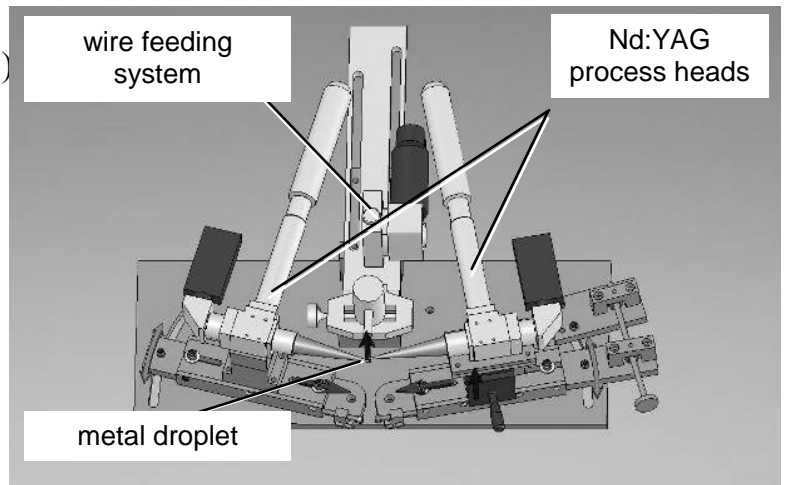

Fig. 5 Schematic of the experimental setup for laser droplet joining

During the LDJ process, a liquid metal droplet is created at the end of the wire by melting of the wire material during a single laser pulse. The molten material is subsequently placed onto the joining partners to achieve the join- 
ing process. The wire has to move in a controlled way during the pulse, in order to compensate for the upward movement of the melt drop due to self-wetting of the wire [7]. The controlled downward movement of the wire compensates this and ensures the droplet being located within the depth of focus of both laser beams. In the investigations described in this paper, the pulse profile used was rectangular. The molten droplet will be touched on the laminate metallisation and the brazing process takes place. The wire is then retracted as long as the droplet is liquid. The laser energy used in specific tests is indicated in the following discussion of results.

\section{Results and Discussion}

\subsection{Laser Soldering}

For the soldering experiments, the influence of the temperature gradients from room temperature to the preheating step and from pre-heating to the soldering step were investigated, as well as the influence of dwell time at the pre-heating and soldering temperatures. An exemplary temperature-time profile is shown in figure 6 and the test parameters are indicated. The temperature of the irradiated solder joint was measured with the pyrometer and the laser power was controlled in a closed loop in order to obtain the designated temperature gradient. The soldering experiments showed a good wetting behaviour of the solder paste on the silver pads and copper connectors (wires or SO8leads). The temperature gradient between room temperature $T_{0}$ and the pre-heating temperature $T_{1}$ is of special interest for the activation of the flux. The dwell time $t_{1}$ at the pre-heating temperature $T_{1}$ leads to a cleaning process of the pads and a better wetting behaviour of the solder during the dwell time $t_{2}$. When this temperature gradient $\Delta T_{1}$ between room temperature $T_{0}$ and the pre-heating temperature $T_{1}$ was too high, small solder droplets were splattered on the pads and short-circuits between the connectors were possible. On the other hand, when the temperature gradient $\Delta \mathrm{T}_{1}$ was chosen too low, oxidation of the pads led to a poor wetting quality. The second temperature gradient $\Delta \mathrm{T}_{2}$ (between pre-heating $\mathrm{T}_{1}$ and the temperature of the solder at liquid phase $T_{2}$ ) and the dwell time $t_{2}$ are responsible for the diffusion process between the liquid solder and the pad as well as the solder and the connector.

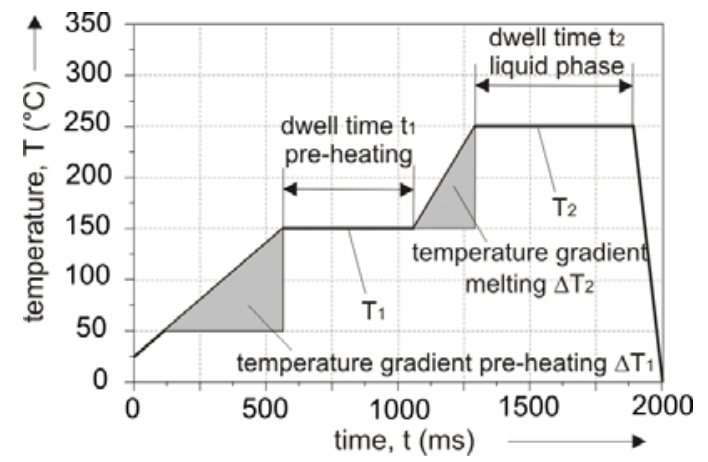

Fig. 6 Exemplary temperature-time profile for laser soldering
For the investigations on LTCC/PZT laminates with screen-printed silver pads - as described in 2.1 - a broad process window can be seen, compare figure 7 . The grey bars show parameters which led to a good wetting behaviour with wetting angles between $\alpha=30^{\circ}$ and $\alpha=85^{\circ}$ on the silver pad. The thickness of the pad $\left(t_{P}=20 \mu \mathrm{m}\right.$ resp. $\left.t_{P}=34 \mu \mathrm{m}\right)$ showed no significant influence on the process parameters. The connector used was a copper wire with a diameter of $\mathrm{d}_{\mathrm{W}}=200 \mu \mathrm{m}$.

The laser soldering experiments were successful for pre-heating temperatures of $\mathrm{T}_{1}=100^{\circ} \mathrm{C}$ or $\mathrm{T}_{1}=150{ }^{\circ} \mathrm{C}$ and temperature gradients between room temperature $\mathrm{T}_{0}$ and the pre-heating temperature $\mathrm{T}_{1}$ of $\Delta \mathrm{T}_{1}=150 \mathrm{~K} / \mathrm{s}$ and $\Delta \mathrm{T}_{1}=600 \mathrm{~K} / \mathrm{s}$. The flux was activated and nearly no spilled material was observable around the solder joint. A lower temperature gradient resulted in a long soldering period and a degrading wetting behaviour. When the value was higher, a disruption of the solder paste was observed frequently. Dwell times on this temperature level of $t_{1}=300 \mathrm{~ms}$ up to $\mathrm{t}_{1}=600 \mathrm{~ms}$ supported the expansion of the solder paste and the vaporisation of the flux. If the dwell time at the preheating temperature $T_{1}$ exceeded $t_{1}=600 \mathrm{~ms}$, the wetting behaviour of the solder decreased. It is supposed that oxidation processes are responsible for this result.

It was possible to reach the second temperature level of $\mathrm{T}_{2}=\mathrm{T}_{\text {melt }}+30^{\circ} \mathrm{C}$ with temperature gradients between $\Delta \mathrm{T}_{2}=125 \mathrm{~K} / \mathrm{s}$ and $\Delta \mathrm{T}_{2}=600 \mathrm{~K} / \mathrm{s}$. As with pre-heating, a higher value led to spilling of the solder; a lower value to a poor wetting quality. The solder has to be held in liquid phase for at least $t_{2}=300 \mathrm{~ms}$ up to $t_{2}=1000 \mathrm{~ms}$. Only with a relatively low dwell time a good wetting behaviour is detectable. Longer periods are capable of damaging the substrate or delamination of the pad.

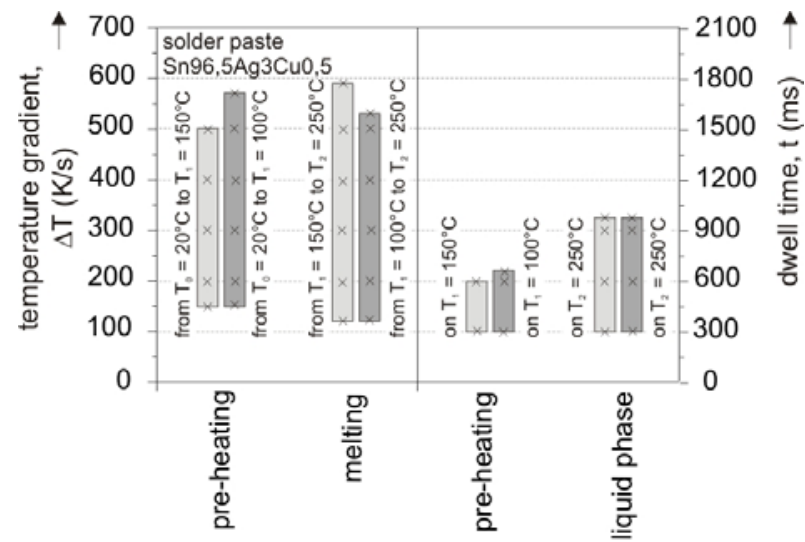

Fig. 7 Process window for laser soldering of $\mathrm{Cu}$ wires $\left(\mathrm{d}_{\mathrm{W}}=200 \mu \mathrm{m}\right)$ on LTCC with Ag pads
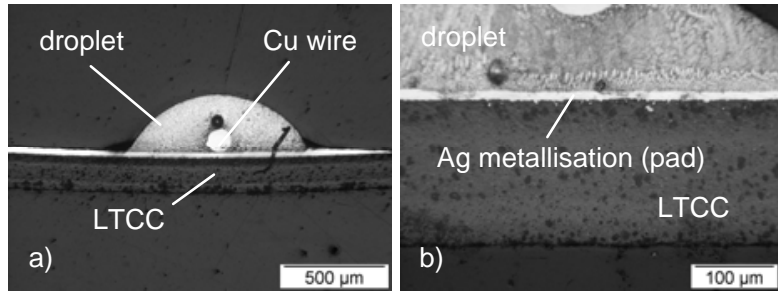

Fig. 8 Cross-section of a solder joint on LTCC with Ag $\operatorname{pad}\left(\mathrm{t}_{\mathrm{P}}=20 \mu \mathrm{m}\right) ; \mathrm{Cu}$ wire $\left(\mathrm{d}_{\mathrm{W}}=200 \mu \mathrm{m}\right)$; solder Sn96.5Ag3Cu0.5

a) overview; b) detail 
In figure 8, a typical cross-section of a laser solder joint is shown. Intermetallic phases between the silver pad and the $\mathrm{SnAgCu}$ solder can be observed to a minor degree. Such phases of $\mathrm{Ag}_{3} \mathrm{Sn}$ are typical for $\mathrm{Sn}$-/Ag-based solder materials. Around the copper wire, intermetallic phases of the type $\mathrm{Cu}_{3} \mathrm{Sn}$ and $\mathrm{Cu}_{6} \mathrm{Sn}_{5}$ can be found. These phases are also typical for solder joints made with $\mathrm{Sn}$-/Ag-solder pastes. During the diffusion process, the copper wire will be solubilised and intermetallic phases are formed at the interface between copper and solder. Especially the $\mathrm{Cu}-/ \mathrm{Sn}$ phases are brittle. They may lead to failures during the lifetime of the joints due to cracking.

In tensile tests, samples with single copper wires used as connectors yielded no analysable results because the wires were destroyed before failure of the solder joints occurred. Thus, for mechanical strength testing of the solder joints, SO8 components were used. In table 1, the process parameters for soldering of SO8 leads of copper are described.

\begin{tabular}{|l|c|c|c|c|}
\hline & $\begin{array}{c}\Delta \mathrm{T}_{1} \text { from } \\
20^{\circ} \mathrm{C} \text { und } \\
150^{\circ} \mathrm{C} \\
{[\mathrm{K} / \mathrm{s}]}\end{array}$ & $\begin{array}{c}\text { dwell } \\
\text { time } \mathrm{t}_{1} \text { on } \\
150^{\circ} \mathrm{C} \\
{[\mathrm{s}]}\end{array}$ & $\begin{array}{c}\Delta \mathrm{T}_{2} \text { from } \\
150^{\circ} \mathrm{C} \text { to } \\
250^{\circ} \mathrm{C} \\
{[\mathrm{K} / \mathrm{s}]}\end{array}$ & $\begin{array}{c}\text { dwell } \\
\text { time } \mathrm{t}_{2} \text { on } \\
250^{\circ} \mathrm{C} \\
{[\mathrm{s}]}\end{array}$ \\
\hline $\begin{array}{l}\text { solder } \\
\text { profile A }\end{array}$ & 150 & 0,6 & 125 & 1,0 \\
\hline $\begin{array}{l}\text { solder } \\
\text { profile B }\end{array}$ & 325 & 0,45 & 360 & 0,65 \\
\hline $\begin{array}{l}\text { solder } \\
\text { profile C }\end{array}$ & 500 & 0,3 & 600 & 0,3 \\
\hline $\begin{array}{l}\text { solder } \\
\text { profile D }\end{array}$ & 750 & 1,25 & 750 & 1,5 \\
\hline
\end{tabular}

Table 1 Process parameters for soldering experiments

With the exception of the solder profile $\mathrm{D}$, all profiles resulted in an acceptable mechanical strength joint, as seen in figure 9. The profiles $\mathrm{A}$ to $\mathrm{C}$ have temperature gradients as well as dwell times in the specified process window. Only profile D has higher temperature gradients and longer dwell times. Onset of delamination and the formation of cracks at the interface between pad and LTCC were the reasons for a lower strength and an early failure.

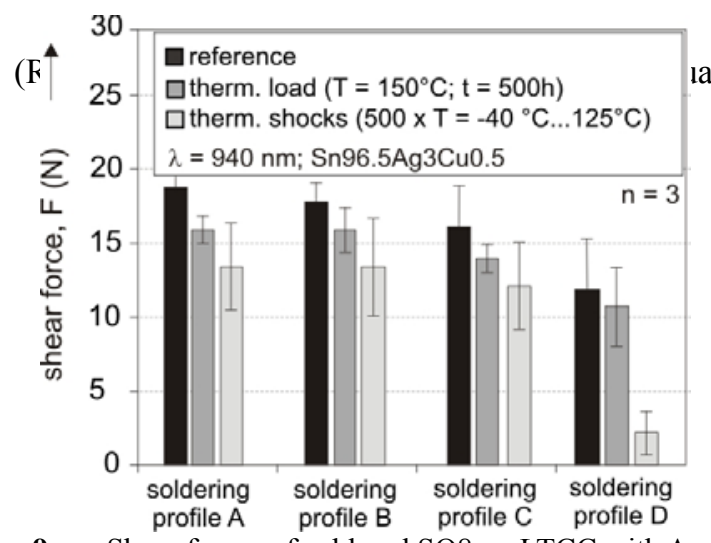

Fig. 9 Shear forces of soldered SO8 on LTCC with Ag pads $\left(t_{P}=20 \mu \mathrm{m}\right)$ before $/$ after artificial aging

A thermal load of $\mathrm{T}=150{ }^{\circ} \mathrm{C}$ was not critical for the solder joints made with the profiles $\mathrm{A}$ to $\mathrm{C}$. The shear force decreased only by $\mathrm{F}=2 \ldots 3 \mathrm{~N}$ after $\mathrm{t}=500 \mathrm{~h}$ related to the reference. However, the thermal shock tests between $\mathrm{T}=-40{ }^{\circ} \mathrm{C}$ and $\mathrm{T}=125^{\circ} \mathrm{C}$ with $\Delta \mathrm{T}=30 \mathrm{~K} / \mathrm{min}$ at a dwell time per temperature of $\mathrm{t}=15 \mathrm{~min}$ were detrimental to the solder joints. After 500 shocks the shear strength decreased from $\mathrm{F} \sim 18 \mathrm{~N}$ to $\mathrm{F} \sim 12 \ldots 14 \mathrm{~N}$ and the standard deviation increased. The reason for this observation was thought to be a formation of cracks at the copper leads of the SO8. There the detrimental intermetallic phases $\mathrm{Cu}_{6} \mathrm{Sn}_{5}$ and $\mathrm{Cu}_{3} \mathrm{Sn}$ in combination with the stiffness of the SO8 chip during the thermal shock test entail the decreasing strength. For solder contacts with single wires, such behaviour was not observed. Because of the low stiffness of the wire, formability outside of the joint is possible and only low shear forces are induced during a thermal shock test.

Further investigations have to deal with the resistance of solder joints to the effects of vibration. This test is of importance for the use of contacted LTCC/PZT laminates in automotive assemblies for e.g. noise absorption.

\subsection{Laser Droplet Joining}

As discussed in 2.3, laser droplet joining allows the creation of more temperature stable joints by the use of e.g. brazing material. The high thermal load and high temperature gradient during the droplet joining process demands controlled droplet energies to avoid the creation of cracks in the LTCC as well as delamination of the pads. However, the droplet energy has to be high enough to allow a wetting and brazing process. The droplet energy $Q_{l}$ is generated by absorption of the laser radiation and is dependent on the pulse energy and on the physical properties of the wire. A part of the accumulated heat is conducted from the formed droplet to the wire $\left(Q_{c}\right)$ and heat losses by vaporization $\left(Q_{v}\right)$ and radiation $\left(Q_{r}\right)$ are also present during formation of the droplet. Further, the heat $Q_{g}$ is transferred to the shielding gas by convection. The heat balance of a droplet is consequently described by:

$Q=Q_{l}-Q_{c}-Q_{v}-Q_{r}-Q_{g}$

The required energy of a laser pulse $E_{P}$ can be estimated with respect to the average absorption coefficient $A$ and some simplifications $[8,11]$ and accordingly, the pulse duration $t_{D}$ for a specific pulse power $P$ can be assessed by: ary 21,2011$)$

$E_{P}=P \cdot t_{D}=\frac{Q_{1}}{A}$.

Consequently, the parameters for the creation of a molten pendant droplet of specific heat content can be estimated. For an effective melting of wire material by conduction, the pulse duration should be adequately long. However, considering the vaporisation effect, the laser power should not be too high $[9,10]$.

To realise temperature stable joints on LTCC/PZT laminates, in experimental studies a brazing wire from Braztec with the composition B-Cu75AgP-645 (Ag18Cu75P7) and a diameter of $\mathrm{d}_{\mathrm{W}}=1 \mathrm{~mm}$ was used. The melting point is $\mathrm{T}_{\text {melt }}=645^{\circ} \mathrm{C}$. A possible process window can be found with pulse energies between $\mathrm{E}_{\mathrm{P}}=17 \ldots 26 \mathrm{~J}$ and rectangular pulse profiles with a pulse duration of $\mathrm{t}_{\mathrm{D}}=20 \mathrm{~ms}$. 
In figure 10, four cross-sections of brazed copper wires on silver metallised LTCC are shown. The wetting angle varies from specimen to specimen even though the process parameters were constant. This, we believe, is due to the still not reproducible droplet dimensions for a given pulse energy. Further work is required to solve this particular problem in laser droplet joining. From the view of process technology it can be seen that a good diffusion zone between the brazing material and the silver pad is attainable. There was no delamination and no significant leaching. Also, the diffusion of the copper wire into the brazing material shows a good electrical connection.
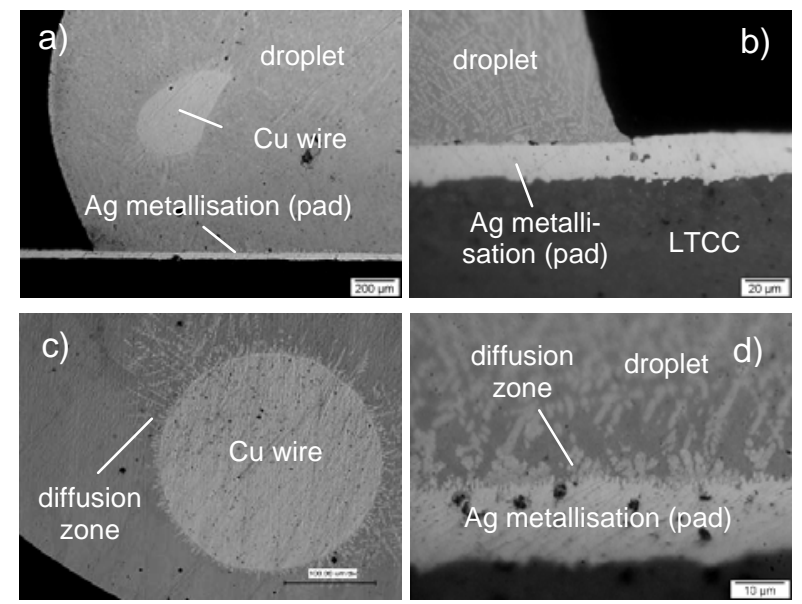

Fig. 10 Cross-sections of laser droplet joints on LTCC with Ag pads $\left(t_{\mathrm{P}}=20 \mu \mathrm{m}\right) ; \mathrm{Cu}$ wire $\left(\mathrm{d}_{\mathrm{W}}=200 \mu \mathrm{m}\right)$; brazing material $\mathrm{Ag} 18 \mathrm{Cu} 75 \mathrm{P} 7\left(\mathrm{~d}_{\mathrm{W}}=1 \mathrm{~mm}\right)$ a) overview; b) detail wetting on Ag pad; c) diffusion zone at the wire; d) diffusion zone at the $\mathrm{Ag}$ pad

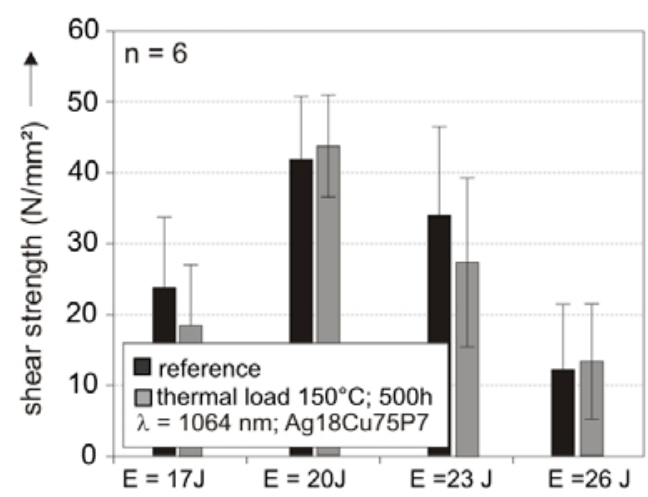

Fig. 11 Shear strength of laser droplet joints on LTCC with Ag pads $\left(t_{\mathrm{P}}=20 \mu \mathrm{m}\right)$ before / after artificial aging

The mechanical strength of the brazing joints realised by LDJ was also investigated. Here the size of the droplets was still large enough to test the shear strength directly at the placed droplets. At pulse energies between $E_{\mathrm{p}}=20 \mathrm{~J}$ and $E_{P}=23 \mathrm{~J}$ the highest values of shear strength were achieved. After thermal ageing at $\mathrm{T}=150{ }^{\circ} \mathrm{C}$ for $\mathrm{t}=500 \mathrm{~h}$, no significant decrease was observable. Pulse energies un$\operatorname{der} E_{p}=20 \mathrm{~J}$ or exceeding $E_{\mathrm{p}}=23 \mathrm{~J}$ led to a decreased mechanical strength. At high pulse energies, the droplets were overheated and first cracks were induced under the pads in the LTCC/PZT laminate after the brazing wire was retracted. These cracks will lead to a failure of the connection.
At low pulse energies, the wetted area was minimised and the connection was generated with a low reproducibility. An increase of the standard deviation of the shear strength of the joints could be observed. The shear strengths of the laser droplet joints produced with varying pulse energies are shown in fig. 11.

The tendency of the joints to form cracks depends not only on the heat stored in the droplet but also on the thickness of the pads. A pad thickness of at least $t_{p}=20 \mu \mathrm{m}$ helps to realise crack-free connections. If thin film metallisation is used, nearly all parameters resulted in cracks, as shown in figure 12. Here a PZT ceramic was used with $\mathrm{a} \mathrm{Cu} / \mathrm{Ni}$ pad with a thickness of $\mathrm{t}_{\mathrm{p}}=0.4 \mu \mathrm{m}$ and without a LTCC cover.

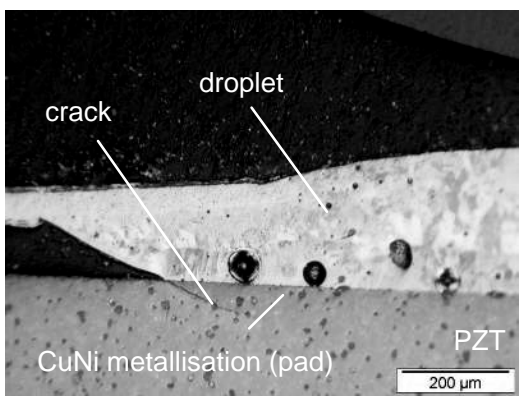

Fig. 12 Cross-section of a laser droplet joint on PZT with CuNi-pad $\left(\mathrm{t}_{\mathrm{P}}=0.4 \mu \mathrm{m}\right)$; brazing material $\operatorname{Ag} 18 \mathrm{Cu} 75 \mathrm{P} 7\left(\mathrm{~d}_{\mathrm{W}}=1 \mathrm{~mm}\right)$; crack in PZT

\section{Conclusion}

By the use of laser soldering or laser droplet joining it is possible to create mechanically stable joints on thin metallised active LTCC/PZT laminates. Because of a fast dissolution of the metallisation at high joining temperatures, the process temperature has to be kept as low as possible. However, a compromise between a sufficiently long time for reliable wetting / diffusion processes and a limited process time to avoid cracks or delamination is of importance. The results for soldering show a broad process window. By the laser droplet joining process brazing joints are realisable, but because of a still variable droplet dimension, reproducible joints were difficult to obtain and future work will have to address better control of the energy input.

\section{Acknowledgment}

The authors gratefully acknowledge the support of this work granted by the German Research Foundation (SFBTR39 - "PT-PIESA") as well as the Fraunhofer Institute for Ceramic Technologies and Systems (IKTS) Dresden.

\section{References}

[1] Neugebauer, S.; Albert, F.; Schmidt, M.; Frick, T.: Laser Based Contacting Of Thin Metal Coated Active Elements. In: LIA (Hrsg.): Proc. of the 27th International Congress on Applications of Lasers and Electro-Optics ICALEO, 2008, Paper M308

[2] Kastens, M; Schmidt, M.: Laserkontaktierung integrierter aktiver Elemente - Strategien zur laserbasierten Kontaktierung komponentenintegrierter Piezowandler in Leichtbaustrukturen. In: Werkstatttechnik Online. Vol. 11/12 2007, VDI, Düsseldorf, 2007 
[3] Scheithauer, U.; Flössel, M.; Uhlig, S.; Schönecker, A.; Gebhardt, S.; Michaelis, A.: „Piezokeramische Fasern, Faserkomposite und LTCC-Module zur Integration in Leichtbaustrukturen", Verbundwerkstoffe; 17. Symposium Verbundwerkstoffe und Werkstoffverbunde, Wiley-VCH, 2008

[4] Rübner, M.; Körner, C.; Singer, R.: Integration of Piezoceramic Modules into Die Castings - Procedure and Functionalities. In: Advances in Science and Technology, Vol. 56, 2008

[5] Datasheet Heraeus HeraLock ${ }^{\circledR}$ Tape - HL2000 (http://www.heraeus-thickfilm.com/en/products applications/ltccmaterials/ltcc_materials_1.aspx)

[6] Flössel, M.; Gebhardt, S.; Schönecker, A.; Michaelis, A.: Development of a Novel Sensor-ActuatorModule with Ceramic Multilayer Technology, In: Journal of Ceram. Sci. Tech., 01[01]55-58, 2010

[7] Geiger, M.; Jahrsdörfer, B.; Schmidt, M.: Laser Droplet Weld - An Innovative Joining Technology. In: Production Engineering - Annals of the WGP, Vol. X/2, 2003

[8] Albert, F.; Schmidt, M.: Laser Droplet Joining Systems, Process and Applications. In: WLT (Hrsg.): Proc. of the 5th International WLTConference on Lasers in Manufacturing, Stuttgart, AT-Fachverlag, 2009

[9] Kokalj, T., Klemenčič, J., Mužič, P., Grabec, I., Govekar, E.: Analysis of the laser droplet formation process. In: Journal of manufacturing science. Trans. of ASME, Vol. 128, No. 1, 2006

[10] Kastens, M.; Schmidt, M.: Laser Droplet Welding Bonding on Thin Substrates. In: Geiger, M.; Otto, A. (Hrsg.): Proc. of the LANE 2007, Meisenbach, Bamberg, 2007

[11] Govekar, E.; Jerič A.; Neugebauer S., Weigl M.; Urmoneit U.; Schmidt M.: Laser Droplet Generation - Application to Droplet Joining. In CIRP Annals Manufacturing Technology, Paper E-19R2, 2009

(Received: November 17, 2009, Accepted: February 21, 2011) 